\title{
Correction to: Non-parallel text style transfer with domain adaptation and an attention model
}

\author{
Mingxuan $\mathrm{Hu}^{1}$ (D) Min $\mathrm{He}^{1}$
}

Published online: 10 July 2021

(C) Springer Science+Business Media, LLC, part of Springer Nature 2021

\section{Correction to: Applied Intelligence.}

https://doi.org/10.1007/s10489-020-02077-5

The original article unfortunately contained an error. Few equations in pages 6 and 7 are incorrect. Also, a few data in Table 3 are also incorrect.

The original article has been corrected.

Publisher's note Springer Nature remains neutral with regard to jurisdictional claims in published maps and institutional affiliations.

The online version of the original article can be found at https://doi.org/ 10.1007/s10489-020-02077-5

$\triangle \mathrm{Min} \mathrm{He}$

hemin@ynu.edu.cn

Mingxuan $\mathrm{Hu}$

djspgo@163.com

1 School of Information Science and Engineering, Yunnan University, Kunming 650091, China 